\title{
Experimental Assessment of Water Hammer- Induced Column Separation in Oil-Hydraulic Pipe Flow
}

Marcus Jansson, Magnus Andersson, Maria Pettersson and Matts Karlsson

The self-archived postprint version of this journal article is available at Linköping University Institutional Repository (DiVA):

http://urn.kb.se/resolve?urn=urn:nbn:se:liu:diva-160585

N.B.: When citing this work, cite the original publication.

Jansson, M., Andersson, M., Pettersson, M., Karlsson, M., (2019), Experimental Assessment of Water Hammer-Induced Column Separation in Oil-Hydraulic Pipe Flow, Journal of Fluids Engineering Trancactions of The ASME, 141(10), 101107. https://doi.org/10.1115/1.4043854

Original publication available at:

https://doi.org/10.1115/1.4043854

Copyright: American Society of Mechanical Engineers (ASME)

http://www.asme.org/ 


\title{
Experimental assessment of water hammer induced column
}

\section{separation in oil-hydraulic pipe flow}

\author{
Marcus Jansson \\ Underground Rock Excavation \\ Epiroc Rock Drills AB \\ Örebro 70225 \\ Sweden \\ marcus.jansson@epiroc.com \\ Department of Management and Engineering \\ Linköping University \\ Linköping 58183 \\ Sweden \\ marcus.jansson@liu.se \\ Magnus Andersson \\ Department of Management and Engineering \\ Linköping University \\ Linköping 58183 \\ Sweden \\ magnus.andersson@liu.se \\ Maria Pettersson \\ Underground Rock Excavation \\ Epiroc Rock Drills AB \\ Örebro 70225 \\ Sweden \\ maria.pettersson@epiroc.com \\ Matts Karlsson \\ Department of Management and Engineering \\ Linköping University \\ Linköping 58183 \\ Sweden \\ matts.karlsson@liu.se
}


Journal of Fluids Engineering

\begin{abstract}
Cavitation erosion through water hammer and column separation is a major concern in hydraulic applications such as percussive rock drilling. Cavitation aspects must be considered both in early and late design stages, which require deep knowledge and tools for prediction. In this study, an oil-hydraulic test equipment for water hammer assessment was designed using state-of-the-art simulation tools. Several tests were performed, with and without column separation, showing good repeatability on measured pressures. At higher flow rates, column separation was the dominating feature and several high-pressure peaks with subsequent time delay reduction could be observed. These patterns were affected by the oil temperature, with most substantial changes at lower temperature ranges $\left(<32^{\circ} \mathrm{C}\right)$. Standard transmission line simulations managed to predict the water hammer, but as expected not the column separation which is the theme of future work using this setup.
\end{abstract}

\title{
INTRODUCTION
}

In a hydraulic percussive rock drill, several components will be exposed to large pressure variations during the piston and valve movement. Such hydraulic transients, often referred to as water hammer, are pressure waves caused by changes in flow conditions [1, 2], e.g. due to opening or closing of valves, starting or stopping of pumps etc. Under severe conditions, this may induce column separation and local cavitation erosion, which can reduce machine life expectancy and thus increase service costs [3-6]. To avoid cavitation erosion completely, a conservative design approach is needed, which in turn would result in higher costs and/or lower performance. Thus, even if possible, it is not fruitful to remove cavitation completely in most real-world applications. Here, it might be more efficient to minimize the effects of cavitation by a combination of innovative designs and well-tuned operating conditions. This requires better predictions and understanding of conditions initiating and progressing cavitation. 
In most cases the immediate damage from a water hammer comes from high-pressure transients at the rejoining of a separated liquid column, which might directly damage piping and other components $[7,8]$. This phenomenon occurs when the stretching of the water hammer reaches a critical breaking point [9], whereby vapor bubbles start to form at nucleation sites such as microbubbles of noncondensable gases and small suspended particles [10]. The formation and collapse of these bubbles can be regarded as cavitation, although cavitation in general covers a much wider area, including travelling bubbles in flowing liquids [11]. Both local and distributed column separation following the closing of a shutoff valve have been observed by Adamkowski and Lewandowski $[12,13]$, among others.

Repetitive water hammer with column separation may induce cavitation erosion, which is one of the major failure mechanisms and cause for reduced life span in hydraulic machinery [9]. Cavitation erosion is believed to be caused by two events: shock waves originating from collapsing cavitation bubbles or clouds of bubbles, and formation of microjets from asymmetrically collapsing bubbles $[6,14]$. Both shock waves and micro-jets will induce small regions of plastic deformation to the material, called pits. Overlapping pits is followed by crack initiation/propagation and eventually material loss and possible component failure.

Water hammer phenomena have been studied extensively since the end of the $19^{\text {th }}$ century, with main focus on water pipeline applications. One of the pioneers was Joukowsky [15] who derived a law for the peak piezometric pressure rise from an instantly closing valve. More recently, computational models like method of characteristics [2] have become a widespread method to evaluate hydraulic transients. Different discrete vapor- or cavity models extend the capabilities to include the effects from column separation $[12,16]$. Computational 
fluid dynamics have also been used to evaluate the effects of water hammer [17]. The use of numerical methods for water hammer prediction is however outside the scope of this study.

The fluid properties, pressure levels, and spatiotemporal scales analog to flow in hydraulic rock drills differ considerable from previous mentioned studies on column separation and cavitation. In a hydraulic rock drill (Fig. 1a), a percussive piston is used to repeatedly hit the drills string. Kinetic energy from the piston is transformed to elastic energy in the form of a stress wave that propagates through the drill string into the drill bit, hereby crushing the rock. The piston is hydraulically actuated by the valve, typically more than 100 times per second, which in turn is actuated by the piston. These rapid variations of flow rate and pressure can cause cavitation with potentially erosion damages on various components (Figs. 1b-d).

The environment inside a rock drill is extremely harsh with complex interaction between multiple components and physical phenomena, providing limited measurements applicability while making modelling challenging and physical interpretations difficult. It would, therefore, be desirable to isolate the water hammer under more controlled, yet relevant conditions to study both the column separation and cavitation erosion. To decompose the system into a limited number of coupled physics would not only be valuable to outline the parameter dependencies on the cavitation dynamics, but results could also serve to improving simulationdriven cavitation prediction.

The aim with this study was to develop an oil-hydraulic test equipment to assess water hammer induced column separation under operation-like conditions. State-of-the-art simulation and measurement tools were used to design and evaluate this baseline experimental 
Journal of Fluids Engineering

setup. This rig should be able to create water hammer both with and without column separation, under controlled but varying conditions, that mimics known fundamental features, operating condition aspects, as well as expected trends.

\section{METHOD}

Design concepts for the experimental setup. To produce a water hammer, the fluid needs to be either accelerated or decelerated, preferably in a pipe. Since column separation occur at low pressures, it is most commonly found downstream of a closing valve. The test equipment would thus need to be able to block a steady flow through a pipe, at the upstream end, while recording the following transient effects in the pipe. The conceptual design (Fig. 2) included a pipe with several piezoelectric pressure sensors (P1-P3). A steady flow in the pipe can be stopped by a valve that is manually initiated, while pressure is recorded. The flow rate should be possible to control, e.g. by using orifices of different diameters at the downstream side of the pipe.

To design the system with pressures and flow rates in a range that will create water hammer, both with and without column separation, transients were estimated using a transmission line model (TLM), implemented in the open-source software Hopsan [18] supplemented with an in-house component library. Components were connected using transmission lines with a time delay, allowing the state variables for each component to be calculated independently from state equations of adjacent components $[19,20]$. Hopsan has previous been used successfully to model e.g. aircraft systems [21] and hybrid hydraulic drivetrains [22]. Hopsan only solves for the impedance and wave variables of the TLM 
Journal of Fluids Engineering

elements. It detects and avoids negative pressures but does not include any effects of cavitation and is far from able to simulate column separation. Here, the simulation model (Fig. 7 in the Appendix) was merely used as a design tool to determine dimensions for the valve and operating oil pressure and -flow rates for the system.

The valve itself should be closing fast enough and have a sufficient damping in order not to introduce unnecessary pressure ripples. Pressure levels and flow rates should be adjusted to enable vapor formation and column separation in the pipe. The valve closing speed was affected by both the oil pressure and the valve dimensions. Oil kinematic viscosity and oil density were specified as $46 \mathrm{cSt}\left(4.6^{*} 10^{-5} \mathrm{~m}^{2} / \mathrm{s}\right)$ and $870 \mathrm{~kg} / \mathrm{m}^{3}$, respectively.

The pipe pressure $(\mathrm{p})$ and a proxy of fluid deceleration $(\Delta v / \Delta t)$, obtained from the transmission line model (Fig. 7), was used to estimate the cavitation number $\left(\mathrm{G}_{\mathrm{A}}\right)$

$$
G_{A}=\frac{p}{\rho \frac{\Delta v}{\Delta t} L}
$$

according to Fatjo [23]. This dimensionless parameter describes the relation between pressureand inertial forces and is an indicator of the potential of a flow to cavitate. For higher flow rates, inertial forces seemed to outweigh the pressure forces $\left(G_{A}<1\right)$ and column separation would be expected (Tab. 1). 
Journal of Fluids Engineering

Table 1. Estimated cavitation numbers.

\begin{tabular}{lllll}
\hline Orifice $[\mathrm{mm}]$ & 2 & 3 & 4 & 5 \\
\hline $\mathrm{p}[$ bar $]$ & 59.8 & 57.7 & 53.4 & 47.3 \\
\hline $\begin{array}{l}\Delta \mathrm{v} / \Delta \mathrm{t}\left[\left(\mathrm{m} / \mathrm{s}^{2}\right) * 10^{-}\right. \\
3]\end{array}$ & 1.00 & 2.83 & 6.06 & 9.21 \\
\hline $\mathbf{G}_{A}[-]$ & $\mathbf{9 . 1 0}$ & $\mathbf{3 . 1 0}$ & $\mathbf{1 . 3 4}$ & $\mathbf{0 . 7 8}$ \\
\hline
\end{tabular}

Test equipment set-up. The final test equipment consisted of a $755 \mathrm{~mm}$ long steel pipe, with $\sim 1 \mathrm{~L}$ sized volumes at both sides (Fig. 3 and Fig. 8 in the Appendix). The diameter of the orifice between the two downstream volumes were used to control the flow rate through the pipe. At the upstream- and outlet tanks, accumulators were used to reduce transients at the inlet and outlet respectively. The accumulators were pre-loaded with a nitrogen pressure of half the oil pressure, i.e. 30 bar and 2.5 bar respectively. The first downstream tank had no accumulators since it was used to reflect the water hammer. Dimensions for the pipe and volumes can be found in Tab. 3 in the Appendix.

In the tanks (inlet, downstream and outlet), the static pressure was recorded using piezoresistive pressure sensors and the temperature was measured with a thermocouple (Fig. 9 in the Appendix). Furthermore, the steady-state flow rate was measured at the inlet with a gear type flow meter (Tab. 4 in the Appendix). Along the pipe, the transient pressure was recorded with piezoelectric pressure sensors (Tab. 4) at three different locations: P1=100 mm, P2=380 $\mathrm{mm}$, and P3=660 $\mathrm{mm}$, from the pipe opening. The valve position was measured by laser (Fig. 10 and Tab. 4 in the Appendix), using the valve housing as reference position. 
Measurements setup. The control valve (CV) was operated manually by an electrical switch. For each test, the switch was turned on and the CV opened. This in turn engaged the valve, which closed. After each test, the system was reset by turning of the switch and close the CV. When the valve was opened, the flow went back to its initial steady state-condition. The valve radial gap was, from manufacturing tolerances, approximately $34 \mu \mathrm{m}$. This gap allowed a small leakage of oil when the CV was in the closed position.

The orifice diameter was changed from $1 \mathrm{~mm}$ to $5 \mathrm{~mm}$ in discrete steps of $1 \mathrm{~mm}$. For the $2 \mathrm{~mm}$ and the $4 \mathrm{~mm}$ orifice, effects from the circumferential angular position of the pipe were assessed by performing tests at $0 \mathrm{deg}, 60 \mathrm{deg}, 120 \mathrm{deg}$, and $180 \mathrm{deg}$. Ten tests were performed for each configuration, resulting in a total of 110 tests; the first two for each configuration were discarded, to ensure more steady conditions, and 8 tests for each configuration were used for average (AVG) and standard deviation (STD) parameters.

The inlet pressure was kept constant at 60 bar for all tests. The temperature was not controlled during the experiments, only recorded. The kinematic viscosity of the oil (Shell Tellus S2 V46 [24]) was in the range of $40-90 \mathrm{cSt}\left(4 * 10^{-5}-9 * 10^{-5} \mathrm{~m}^{2} / \mathrm{s}\right)$. The density was $\rho=859 \pm 4$ $\mathrm{kg} / \mathrm{m}^{3}$ and the bulk modulus was $\mathrm{K}=1.52 \pm 2 \mathrm{GPa}$, at atmospheric pressure. For the given conditions, the wave speed was expected to be in the range of $a=1330 \pm 4 \mathrm{~m} / \mathrm{s}$, according to $a=\sqrt{K / \rho}[1]$, assuming a rigid pipe with compressible fluid. The saturation vapor pressure was below $0.5 \mathrm{~Pa}$ at $20^{\circ} \mathrm{C}$, according to estimates [25], and expected to increase with increased temperature [26]. 
The results from the simulations were used for comparison. Both the CV (Fig. 7a) and the valve (Fig. 7b) were replaced with valve position data from the experimental measurements (Fig. 4a). Inlet- and drain pressures were set to the average of the measurements.

\section{RESULTS}

The flow rates were in the range $3.6-82 \mathrm{~L} / \mathrm{min}\left(6^{*} 10^{-5}-1.4^{*} 10^{-3} \mathrm{~m}^{3} / \mathrm{s}\right)(T a b .2)$. Results for 1 $\mathrm{mm}$ orifice were similar to $2 \mathrm{~mm}$ orifice, with lesser amplitude, and therefore excluded for brevity. The cross-sectional averaged velocities were estimated from the mean volumetric flow rates. The deviation at each flow rate level was insignificant. The variation in temperature was more significant. At intermediate to higher flow rates, the temperature tended to increase for successive runs. At low flow rates, the opposite was observed. The leakage through the radial gap increased with higher flow rates, from $2 \mathrm{~L} / \mathrm{min}$ at the lowest flow rate to $4 \mathrm{~L} / \mathrm{min}$ at the highest flow rate. Relative to the steady-state flow rate however, the leakage still decreased with higher flow rates (Tab. 2). The Reynolds number varied from $\mathrm{Re}=400$ for the lowest flow rate to $\operatorname{Re}=4400$ for the highest flow rate.

Table 2. Flow rate and temperature measurements given as AVG $\pm S T D$ [MIN-MAX].

\begin{tabular}{|c|c|c|c|c|}
\hline Orifice [mm] & 2 & 3 & 4 & 5 \\
\hline $\begin{array}{l}\text { Volumetric } \\
\text { flow rate }[\mathrm{L} / \mathrm{min}]\end{array}$ & $\begin{array}{l}16.3 \pm 0.04 \\
\text { (low) }\end{array}$ & $\begin{array}{l}35.8 \pm 0.05 \\
\text { (intermediate) }\end{array}$ & $\begin{array}{l}58.1 \pm 0.05 \\
\text { (high) }\end{array}$ & $\begin{array}{l}81.5 \pm 0.22 \\
\text { (high) }\end{array}$ \\
\hline Flow velocity $[\mathrm{m} / \mathrm{s}]$ & 3.46 & 7.60 & 12.3 & 17.3 \\
\hline Temp. $\left[{ }^{\circ} \mathrm{C}\right]$ & $\begin{array}{l}26.7 \pm 1.5 \\
{[24.1-28.6]}\end{array}$ & $\begin{array}{l}39.4 \pm 2.2[35.6- \\
41.8]\end{array}$ & $\begin{array}{l}41.8 \pm 1.3 \\
{[39.6-43.1]}\end{array}$ & $\begin{array}{l}33.4 \pm 4.5 \\
{[27.5-39.0]}\end{array}$ \\
\hline Relative leakage [-] & 0.14 & 0.10 & 0.06 & 0.05 \\
\hline
\end{tabular}


Valve dynamics. Increased flow rate reduced the valve closing time and resulted in overall higher valve velocities (Fig. 4). The largest difference in valve closing could be seen after the valve enters the pipe opening (Figs. $4 \mathrm{~b}$ and $4 \mathrm{c}$ ), where the lowest flow rate $(2 \mathrm{~mm}$ ) experienced a significant slow-down of the valve velocity, while larger flow rates ( $3-5 \mathrm{~mm}$ ) showed almost no such effects. Standard deviation of valve position was less than $0.04 \mathrm{~mm}$, or $2 \%$ of the stroke length. The highest valve velocities were reached just before the valve enters the pipe. An increase in flow rate resulted in higher valve velocity.

Pipe pressure response. For low flow rate (Fig. 5a), the water hammer was the dominating feature, with a phase delay of around $2.2 \mathrm{~ms}(\mathrm{f}=455 \mathrm{~Hz})$, in line with well-known water hammer theory $[1,2]$ and the expected wave speed. The time delay between measuring points were also as expected. No signs of cavitation were seen. Damping from various losses was extensive, and after $20 \mathrm{~ms}$ from valve closing most transients were suppressed. At intermediate flow rate (Fig. 5b), the water hammer amplitude increased as expected, but with initial evidence of cavitation onset, observed as short-duration pressure spikes in the first two water hammer pulsations. The overall pressure variations were at this flow rate dominated by the water hammer effects, and the phase delay was equal to the measurements at lower flow rates. At higher flow rates (Fig. 5c), the pressure response appeared to be governed by cavitating flow, with less periodic water hammer patterns and much higher frequency content. Here, four highpressure peaks with subsequent time delay reduction could be observed, before returning to the expected water hammer frequency. Pressure pulsations before the first collapse, and between successive collapses, seemed to appear at twice the water hammer frequency $(\mathrm{f}=916$ $\mathrm{Hz}$ ). At the highest flow rate (Fig. 5d), the most elevated pressure amplitudes could be seen, 
with a clear delay to the first collapse $(15 \mathrm{~ms})$ compared to the former cases $(4 \mathrm{~mm} \approx 8 \mathrm{~ms}$, $3 \mathrm{~mm} \approx 7 \mathrm{~ms}$ ). Contrary, here the following collapses seemed to appear more frequently.

For flow rates up to cavitation inception (Fig. 5a), the TLM simulations performed well with initial water hammer transients highly similar to the measurements. The damping from losses and leakage were not as prominent in simulations and a small difference in time delay could be observed. At intermediate flow rate (Fig. 5b), the model still captures the overall characteristics, but not the short-duration pressure peaks. At increased flow rate (Figs. $5 \mathrm{c}$ and $5 d)$, simulations could only predict transients until the point of cavitation ( $\approx 5-6 \mathrm{~ms})$. During column separation, the TLM results showed no similarity to the measurements. After a few odd pulsations, the simulations quickly returned to water hammer behavior. Column separation and rejoining could not be observed in the simulations.

Oil temperature dependencies and pipe angular effects. The variation in oil temperature showed a clear impact on column separation patterns (Fig. 6), where an increase in temperature reduced the pressure amplitude and number of collapses (Fig. 6a). Within the tested temperature span, however, the reduction in pressure amplitude seemed to only be substantial for lower temperature ranges (Fig. $6 \mathrm{~b},<32^{\circ} \mathrm{C}$ ). The time to the first collapse (Fig. 6a, T1) did not change markedly against temperature (Fig. 6c, $1^{\text {st }}$ ), while an increased time delay was noticed for the subsequent collapses (Fig. 6a, T2 and T3). Again, this effect seemed to be less pronounced for temperature above $32{ }^{\circ} \mathrm{C}$ in this case (Fig. $6 \mathrm{c}, 2^{\text {nd }}$ and $3^{\text {rd }}$ ). In addition, the timing between the second and third collapse appeared insensitive to temperature changes. The circumferential angular test did not show any notable difference between collapse pressure amplitudes (Fig. 6b) nor time delay (Fig. 6c). 
Journal of Fluids Engineering

\section{DISCUSSION}

A test equipment able to produce a water hammer, with and without column separation, in a rigid steel pipe was successfully developed in this study. Several tests were performed at different flow rates, showing good repeatability on measured pressures at different positions along the pipe. Although the valve allowed for a small amount of leakage, which likely would have some damping effects on the transients, the behavior followed expected trends. That is, higher flow rates, with increased inertial forces, resulted in liquid column separation, while the TLM simulations managed to predict the water hammer, but not the column separation. In addition, thermal effect on cavitation seemed to be more prominent at lower temperature ranges $\left(<32^{\circ} \mathrm{C}\right)$, while angular measurements suggest a planar, symmetric pressure wave.

At the lowest flow rate (Fig. 5a), the damping was extensive and the ideal water hammer (Fig. 2) could not be observed. In addition to friction losses, the leakage in the valve was quite large compared to the steady-state flow rate (Tab. 2). Considering these damping effects, the pressure waves appeared as expected according to water hammer theory. At intermediate flow rate (Fig. 5b), the relative leakage was reduced and seemed to have less contribution to the damping. The pressure pulsations showed similarities to the ideal water hammer with some effects from friction losses. In addition to the water hammer, narrow high-

pressure spikes could be observed at the initial waves, which indicates separation and rejoining of a liquid column. Further increase in flow rate (Fig. 5c) caused a separation of the liquid column, with a completely disrupted water hammer for a longer duration ( $20 \mathrm{~ms})$. Here, the most prominent feature of the pressure signal was the high-pressure peaks from the liquid column rejoining/cavitation bubble collapse, which seemed to increase with the oil flow rate 
(Fig. 5d), as expected from previous work $[12,13]$. The low-amplitude pressure wave patterns observed between cavitation collapses, may suggest a reduction in liquid column length (or increase of gas content), findings which were more distinct in the central part of the pipe (Figs. $5 c$ and $5 d, P 2)$. This might be caused by cavity zones that appear primarily at the valve, but which also have been observed at other cross-sections along the pipe [13].

The TLM performed, as expected, well until column separation (Figs. 5a and 5b). The leakage in both the model and in experiments were similar, but the damping effects on the pressure transients were more visible in the experiments. The TLM were not able to account for the column separation (Figs. $5 c$ and $5 d$ ); however, it accurately predicted the behavior up to the point of cavitation inception. Considering the speed of the simulations, this tool is valuable in applications with no cavitation or finding the onset of cavitation.

The cavitation phenomena showed clear dependency on the oil temperature in the lower range (Figs. $6 \mathrm{~b}$ and $6 \mathrm{c}$ ), with more frequent and high-amplitude collapses compared to more elevated temperatures. In the recommended working range for the oil $\left(35-50{ }^{\circ} \mathrm{C}\right)$, no such dependency was observed (Figs. 6b and 6c). Higher temperatures were not investigated. Temperature control and cooling was not considered in this study and the temperature tended to rise when the test rig was operated (Tab. 2). The increase in temperature was more prominent for higher flow rates. It could be observed that the effects from increased temperature, longer cavitation duration and lower collapse amplitude, are similar to those of increased air content [27]. Although the temperature only showed major influence at lower temperature ranges, typically outside operating conditions, the cavitation sensitivity to temperature needs further investigation. 
The pipe diameter was considered representative of the conditions in a rock drill. The pipe length was limited by feasibility in both production and operation. A long pipe was desired since this meant lower frequencies, which are easier to measure, and makes the valve closing time short compared to the wave travel time. The volume at the downstream end of the pipe reflects and reverses the incoming pressure wave. This was vital for the water hammer to continue. The valve closing speed was increased at higher flow rates, probably a result from the reduced pressure in the pipe. For simplicity, the CV and the valve (Fig. 7a) was replaced with experimental data. This approach was sufficient for concept evaluation and to assess the domain of validity for the TLM model. For further studies, with more emphasis on the numerical results, it might be desirable to implement a more accurate valve model.

The inertia of the gear type flow meters made them suitable to measure only the steady-state flow in the test equipment, and changes in flow rate could not be captured appropriately. Thus, the leakage due to valve clearance had to be determined when the system had reached its new steady-state. The leakage flow rate was in the lower part of the measuring range, especially in the case with a $5 \mathrm{~mm}$ orifice, which used the larger model flow meter. However, the measurements did still provide good estimations for the size and trends of the leakage. Although the leakage may contribute to the dissipation of pressure waves it does not affect the overall characteristics of the water hammer and column separation.

To conclude, the test equipment with a fast-closing valve successfully produced a water hammer in mineral oil, both with and without column separation. Simulations showed good agreement for pure water hammer but failed to predict column separation. Column separation seemed to be affected by the oil temperature in certain ranges and needs further investigation. 
Journal of Fluids Engineering

The set-up developed here is well suited for further analysis of cavitation phenomena, both via direct experiments as well as providing reference data for numerical simulations.

\section{ACKNOWLEDGMENT}

This research was funded by Epiroc Rock Drills AB, Örebro, Sweden.

\section{AUTHOR CONTRIBUTIONS}

Study conception and design: MJ, MA, MP and MK. Acquisition of data: MJ. Analysis and interpretation of data: MJ, MA and MK. Drafting of manuscript: MJ. All authors edited and revised the manuscript. The final manuscript has been read and approved by all authors.

\section{DECLARATION OF INTEREST}

M. Jansson is an industrial PhD student at Epiroc Rock Drills AB and Linköping University. M. Pettersson is employed at Epiroc Rock Drills AB. The authors have no other conflict of interest to declare.

\section{NOMENCLATURE}

$G_{A}=$ cavitation number

$L=$ pipe length

$p=$ pipe pressure

$\Delta t=$ time difference in fluid velocity change

$\Delta v=$ change in fluid velocity 


\section{APPENDIX}

Table 3. Dimensions.

\begin{tabular}{lll}
\hline & Length $[\mathrm{mm}]$ & Radius $[\mathrm{mm}]$ \\
\hline Tank 1 & 85 & 50 \\
\hline Pipe & 755 & 5 \\
\hline Tank 2 & 85 & 50 \\
\hline Orifice & - & $0.5-2$ \\
\hline Tank 3 & 95 & 50 \\
\hline
\end{tabular}

Table 4. Sensors.

\begin{tabular}{|c|c|c|c|c|c|}
\hline Channel & Position & Type & Model & Range & Accuracy \\
\hline 1 & Ps & Pressure sensor & Druck Ltd PTX & $0-400$ bar & $\pm 0.2 \%$ \\
\hline \multirow[t]{2}{*}{4} & $\mathrm{P} 1$ & Piezoelectric & PCB Piezotronics & & \\
\hline & & pressure sensor & $113 B 22$ & & \\
\hline \multirow[t]{2}{*}{5} & $\mathrm{P} 2$ & Piezoelectric & PCB Piezotronics & & \\
\hline & & pressure sensor & $113 \mathrm{~B} 22$ & & \\
\hline \multirow[t]{2}{*}{6} & P3 & Piezoelectric & PCB Piezotronics & & \\
\hline & & pressure sensor & $113 \mathrm{~B} 22$ & & \\
\hline 2 & P4 & Pressure sensor & Druck Ltd PTX & $0-160$ bar & $\pm 0.2 \%$ \\
\hline 3 & P5 & Pressure sensor & Druck Ltd PTX & $0-9$ bar & $\pm 0.2 \%$ \\
\hline \multirow[t]{2}{*}{7} & Svalve & Laser & Keyence LK-G502 & $230-250$ & \\
\hline & & & & $\mathrm{mm}$ & \\
\hline \multirow[t]{2}{*}{8} & Sref & Laser & Keyence LK-G502 & $230-250$ & \\
\hline & & & & $\mathrm{mm}$ & \\
\hline- & Flow 1 & $\begin{array}{l}\text { Gear type flow } \\
\text { meter }\end{array}$ & Kracht VC1 E-06 459 & $0.4-80 \mathrm{I} / \mathrm{min}$ & $\pm 0.3 \%$ \\
\hline- & Flow 2 & $\begin{array}{l}\text { Gear type flow } \\
\text { meter }\end{array}$ & Kracht VC5 C-07 638 & $1-250 \mathrm{l} / \mathrm{min}$ & $\pm 0.3 \%$ \\
\hline
\end{tabular}

\section{References}

1. Chaudhry, M.H., Applied hydraulic transients. 1979, Springer.

2. Wylie, E.B. and Streeter, V.L., Fluid transients. New York, McGraw-Hill International Book Co., 1978. 401 p., 1978.

3. Knapp, R.T., Daily, J.W., and Hammitt, F.G., Cavitation. 1970: McGraw-Hill.

4. Arndt, R.E., Cavitation in fluid machinery and hydraulic structures. Annual Review of Fluid Mechanics, 1981. 13(1): p. 273-326.

5. Li, S., Cavitation of hydraulic machinery. Vol. 1. 2000: World Scientific.

6. Koivula, T. On cavitation in fluid power. in Proc. of 1st FPNI-PhD Symp. Hamburg. 2000. 
7. Bonin, C., Water-hammer damage to Oigawa power station. ASME Journal of Engineering for Power, 1960. 82: p. 111-119.

8. List, E.J., Burnam, J., Solbrig, R. and Hogatt, J., Vapor cavity formation and collapse: Field evidence for major pipeline damage. 1999.

9. Bergant, A., Simpson, A.R. and Tijsseling, A.S., Water hammer with column separation: A historical review. Journal of fluids and structures, 2006. 22(2): p. 135-171.

10. Brennen, C.E., An introduction to cavitation fundamentals. 2011.

11. Brennen, C.E., Cavitation and bubble dynamics. 2013: Cambridge University Press.

12. Adamkowski, A. and Lewandowski, M., A new method for numerical prediction of liquid column separation accompanying hydraulic transients in pipelines. Journal of fluids engineering, 2009. 131(7): p. 071302.

13. Adamkowski, A. and Lewandowski, M., Investigation of hydraulic transients in a pipeline with column separation. Journal of Hydraulic Engineering, 2012. 138(11): p. 935-944.

14. Kim, K.-H., Chahine, G., Franc, J.-P. and Karimi, A., Advanced experimental and numerical techniques for cavitation erosion prediction. Vol. 106. 2014: Springer.

15. Joukowsky, N., Über den hydraulischen Stoss in Wasserleitungsrohren. 1900, St. Petersbourg. 1 I., $71 \mathrm{p}$.

16. Soares, A.K., Covas, D.I. and Carriço, N.J., Transient vaporous cavitation in viscoelastic pipes. Journal of Hydraulic Research, 2012. 50(2): p. 228-235.

17. Nikpour, M.R., Nazemi, A.H., Dalir, A.H., Shoja, F. and Varjavand, P., Experimental and numerical simulation of water hammer. Arabian Journal for Science and Engineering, 2014. 39(4): p. 26692675.

18. Larsson, J., User's guide to Hopsan. An integrated simulation environment. Linköping University, Aug, 2002.

19. Eriksson, B., Nordin, P. and Krus, P., Hopsan NG, a C++ implementation using the TLM simulation technique. in Conference of Scandinavian Simulation Society, sims' 10, 14th-15th October, Oulu, Finland. 2010.

20. Krus, P. Robust modelling using bi-lateral delay lines for high speed simulation of complex systems. in The The International Symposium on Dynamic Problems of Mechanics, March, 13 to 18, 2011 Maresias Beach Hotel São Sebastião, São Paulo, Brazil. 2011.

21. Andersson, J., et al. Modelling and simulation of heat generation in electro-hydrostatic actuation systems. in Proceedings of the JFPS international symposium on fluid power. 1999. The Japan Fluid Power System Society.

22. Bær, K., L. Ericson, and P. Krus. Modeling of a Series Hybrid Hydraulic Drivetrain for a Light-Duty Vehicle in Hopsan. in 13th Scandinavian International Conference on Fluid Power; June 3-5; 2013; Linköping; Sweden. 2013. Linköping University Electronic Press.

23. Fatjo, G.G.-A., New Dimensionless Number To Predict Cavitation In Accelerated Fluid. International Journal of Computational Methods and Experimental Measurements, 2016. 4(4): p. 484-492.

24. Shell, Technical data on Shell Tellus Oils. Second edition ed. Vol. Second edition. 1967: Shell International Petroleum Company Limited.

25. Shell, Shell Tellus S2 V 46 Safety Data Sheet. 2015.

26. Willingham, C.B., et al., Vapor pressures and boiling points of some paraffin, alkylcyclopentane, alkylcyclohexane, and alkylbenzene hydrocarbons. Journal of Research of the National Bureau of Standards, 1945. 35(3): p. 219-244.

27. KOJIMA, E., M. SHINADA, and K. SHINDO, Fluid Transient Phenomena Accompanied with Column Separation in Fluid Power Pipeline: 1st Report, On the Horizontal Pipeline Downstream of a Valve Instantaneously Closed. Bulletin of JSME, 1984. 27(233): p. 2421-2429. 


\section{List of figures}

Fig. 1. Cavitation in hydraulic rock drills. (a), section of hydraulic percussive rock drill. The piston (red) movement is controlled by the valve (blue) and vice versa. The hydraulic force accelerates the piston that hits the shank, the valve shifts, and the piston movement is reversed. At the time the piston is back to its initial position, the valve has shifted again, and the piston is accelerated towards the shank. The kinetic energy in the piston is transferred to the shank and the drill string as elastic energy. The elastic wave propagates through the drill string and bit (not shown) where the energy is used to crush the rock. Both piston and valve will be exposed to alternating high- and low pressures; transients that may cause cavitation and damage material. (b-d), typical sites of cavitation induced erosion in hydraulic percussive rock

drill. Green arrows indicate areas of severe material damage. (b), axisymmetrical erosion in the vicinity of the piston land. The piston is polished, and the grainy areas have been exposed to cavitation. (c), deep pits of erosive damage in the piston guide. (d), localized erosion in the lowpressure regions of the valve housing.

Fig. 2. Conceptual design of the ideal water hammer. A steady flow will pass through the pipe (from left to right). At a given time, the upstream valve will close the pipe and the following transient effects in the pipe will be recorded by piezoelectric pressure sensors (P1-P3). At the downstream side of the pipe, the pressure wave is reflected in a volume. After the instant closing of an upstream valve, pressure transient will manifest along the pipe, here illustrated from water hammer theory (P1-P3, pressure signals). Pressure and time are normalized with the initial pressure and the characteristic time delay of the pipe, respectively. At the first 
Journal of Fluids Engineering

pressure sensor (P1), the pressure drop can be seen instantaneously. For the downstream sensors (P2 and P3) a time delay can be seen. The opposite is observed for the returning pressure wave, where downstream sensors are affected first. Each low-pressure wave will be followed by a high-pressure wave, and vice versa.

Fig. 3. Test equipment section. Piezoelectric sensors (P1-P3) were positioned in the center (P2) and at each end (P1 and P3) of the investigated $755 \mathrm{~mm}$ steel pipe. The valve is hydraulically controlled with an external control valve. The orifice was used to regulate the flow rate through the system. Not shown are temperature sensor (in first tank), flow meter (at inlet hose), pressure sensors in first, second and third tank.

Fig. 4. Valve closing characteristics. (a)-(c), mean valve movement during closing for 2 to $5 \mathrm{~mm}$ orifice over 8 measurements (STD $<2 \%$ of stroke length). The dash-line highlights when the valve enters the pipe. (a), time vs. position: increased flow rate reduced the closing time of the valve. The differences were more distinguishable in the later stage of valve closing. (b), time vs. velocity: the slow-down of the valve in the $2 \mathrm{~mm}$ orifice configuration was distinct. Although the valve movements in the 3-5 mm configurations were similar, an increase in flow rate resulted in a higher maximum valve velocity. (c), position vs. velocity: for faster closing valves (3-5 mm), the maximum valve speed was achieved when the valve entered the pipe. For the 2 $\mathrm{mm}$ orifice, the slow-down was more prominent and peaked prematurely compared to the other cases.

Fig. 5. Pressure response at valve closing. (a)-(d), piezoelectric pressure signals (P1-P3, Fig. 4) and corresponding results from the TLM simulations at four different flow rates $(2-5 \mathrm{~mm}$ 
orifice). Data shows the mean (black) and standard deviation (shaded area) over eight measurements, together with TLM results (red). The closing valve enters the pipe at $5 \mathrm{~ms}$ (dashed line). (a), low flow rate: system without cavitation and pure water hammer with extensive damping. The characteristics are well captured by the TLM. (b), intermediate flow rate: short-duration pressure peaks suggest cavitation initiation. The TLM still captures the overall characteristics but fail to predict the short-duration pressure peaks. (c, d), high flow rate: large pressure spikes and reduced water hammer effects indicates substantial cavitation. The simulations predict the pressure response until cavitation, whereafter no resemblance can be noticed against experiments.

Fig. 6. Oil temperature and pipe angular position. (a), piezoelectric pressure signals (Fig. 4, P1) at high flow rate (4 $\mathrm{mm}$ orifice) and three different oil temperatures. Higher oil temperature tends to delay cavitation onset (time-to-collapse, $1^{\text {st. }}: T 1,2^{\text {nd. }}: T 2$ and $3^{\text {rd }}: T 3$ ) and reduce the pressure amplitude at collapse $\left(1^{\text {st. }}: A 1,2^{\text {nd }}: A 2\right.$ and $\left.3^{\text {rd }}: A 3\right)$. The time was estimated from moment of valve closing (dashed line). (b, c), Oil temperature versus collapse amplitude and time delay at P1 for the: $1^{\text {st }}(x), 2^{\text {nd }}(0)$ and $3^{\text {rd }}(+)$ collapse, assessed according to $(a)$. Strongest dependences can be seen for lower temperatures $\left(<32^{\circ} \mathrm{C}\right)$, resulting in higher amplitudes (b) with shorter time to collapse (c), while higher oil tempareature ranges were less sensitive. Colors represent different rotation angles of the pipe (green $=0^{\circ}, \mathrm{cyan}=60^{\circ}$, magenta $=120^{\circ}$, black $\left.=180^{\circ}\right)$. The rotation angle affects neither collapse amplitude or time, provided the same oil temperature.

Fig. 7. Transmission Line Model. The test equipment was operated by a control valve (a), which was fed by a variable displacement pump that kept a constant operating pressure. The control 
Journal of Fluids Engineering

valve engages with the valve (b) to stop the pipe flow. The steady flow through the pipe (c) was provided by a variable displacement pump. The system pressure was constant at 60 bar and the flow rate was regulated by the orifice diameter.

Fig. 8. Test setup. The upstream tank with the valve is located to the left and the two downstream tanks, separated by an orifice, to the right. Piezoelectric pressure sensors are positioned along the pipe (middle).

Fig. 9. Silicon pressure sensors and thermoelement. (a), the oil pressure was measured in the tank upstream the pipe with a silicon pressure sensor. The oil temperature was measured with a thermoelement and a multimeter. (b), the pressure was measured both upstream and downstream of the orifice with silicon pressure sensors.

Fig. 10. Laser setup. (a), the two lasers were placed approximately $25 \mathrm{~cm}$ from the valve. (b), one laser measured the valve movement while another laser measured any potential movement of the valve housing.

\section{List of tables}

Table 3. Estimated cavitation numbers.

Table 4. Flow rate and temperature measurements given as AVG \pm STD [MIN-MAX].

Table 3. Dimensions.

Table 4. Sensors. 
(a)

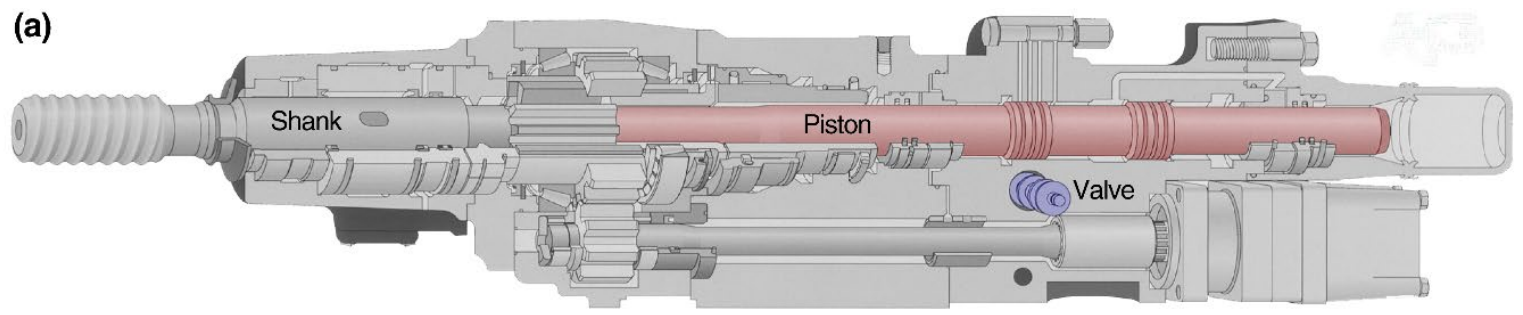

(b)

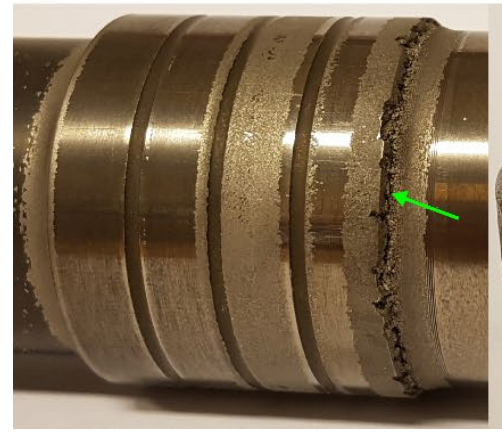

(c)

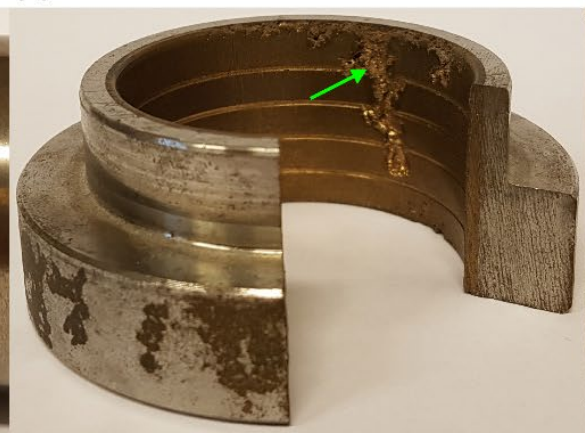

(d)

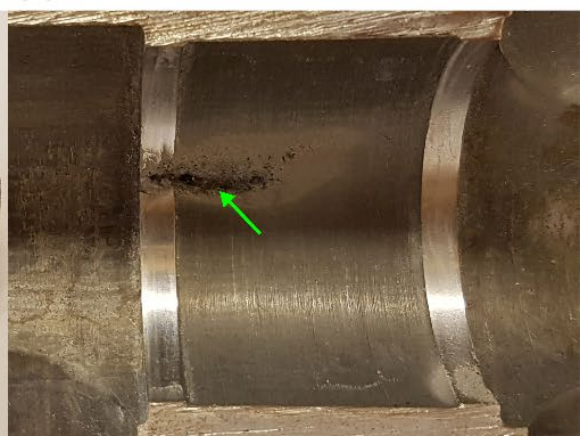

Fig. 2. Cavitation in hydraulic rock drills. (a), section of hydraulic percussive rock drill. The piston (red) movement is controlled by the valve (blue) and vice versa. The hydraulic force accelerates the piston that hits the shank, the valve shifts, and the piston movement is reversed. At the time the piston is back to its initial position, the valve has shifted again, and the piston is accelerated towards the shank. The kinetic energy in the piston is transferred to the shank and the drill string as elastic energy. The elastic wave propagates through the drill string and bit (not shown)\} where the energy is used to crush the rock. Both piston and valve will be exposed to alternating high- and low pressures; transients that may cause cavitation and damage material. (b-d), typical sites of cavitation induced erosion in hydraulic percussive rock drill. Green arrows indicate areas of severe material damage. (b), axisymmetrical erosion in the vicinity of the piston land. The piston is polished, and the grainy areas have been exposed to cavitation. (c), deep pits of erosive damage in the piston guide. (d), localized erosion in the low-pressure regions of the valve housing. 

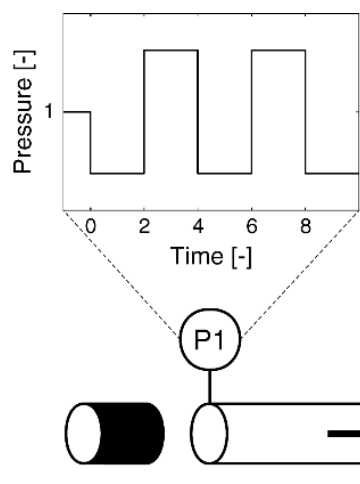

Valve

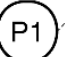

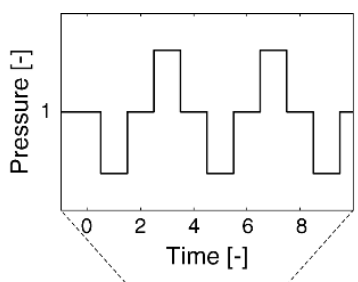

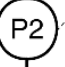

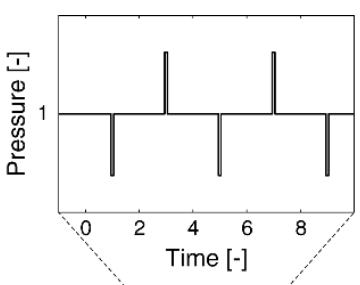

P3
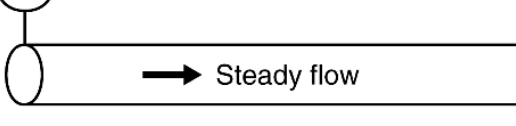

Fig. 2. Conceptual design of the ideal water hammer. A steady flow will pass through the pipe (from left to right). At a given time, the upstream valve will close the pipe and the following transient effects in the pipe will be recorded by piezoelectric pressure sensors (P1-P3). At the downstream side of the pipe, the pressure wave is reflected in a volume. After the instant closing of an upstream valve, pressure transient will manifest along the pipe, here illustrated from water hammer theory (P1-P3, pressure signals). Pressure and time are normalized with the initial pressure and the characteristic time delay of the pipe, respectively. At the first pressure sensor (P1), the pressure drop can be seen instantaneously. For the downstream sensors (P2 and P3) a time delay can be seen. The opposite is observed for the returning pressure wave, where downstream sensors are affected first. Each low-pressure wave will be followed by a high-pressure wave, and vice versa.

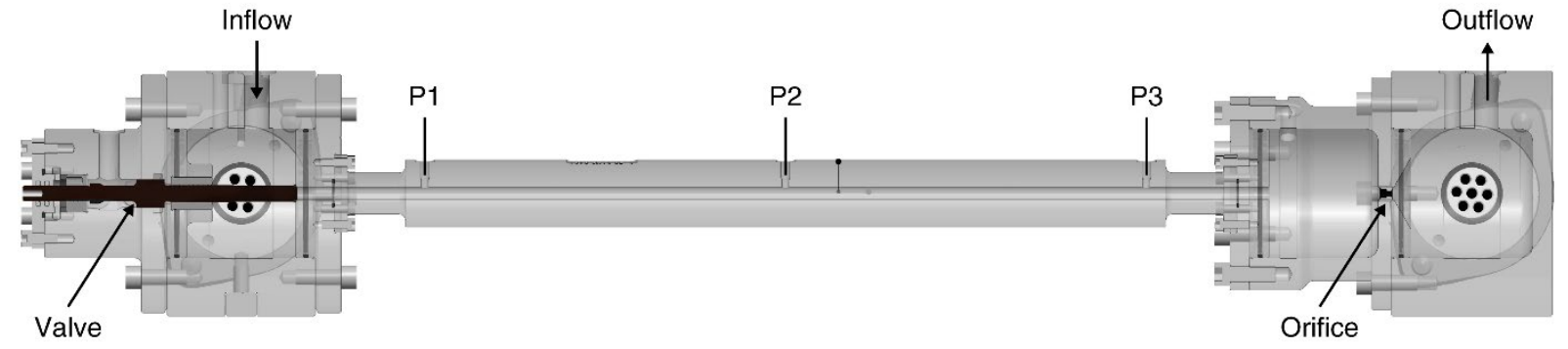

Fig. 3. Test equipment section. Piezoelectric sensors (P1-P3) were positioned in the center (P2) and at each end (P1 and P3) of the investigated $755 \mathrm{~mm}$ steel pipe. The valve is hydraulically controlled with an external control valve. The orifice was used to regulate the flow rate through the system. Not shown are temperature sensor (in first tank), flow meter (at inlet hose), pressure sensors in first, second and third tank. 

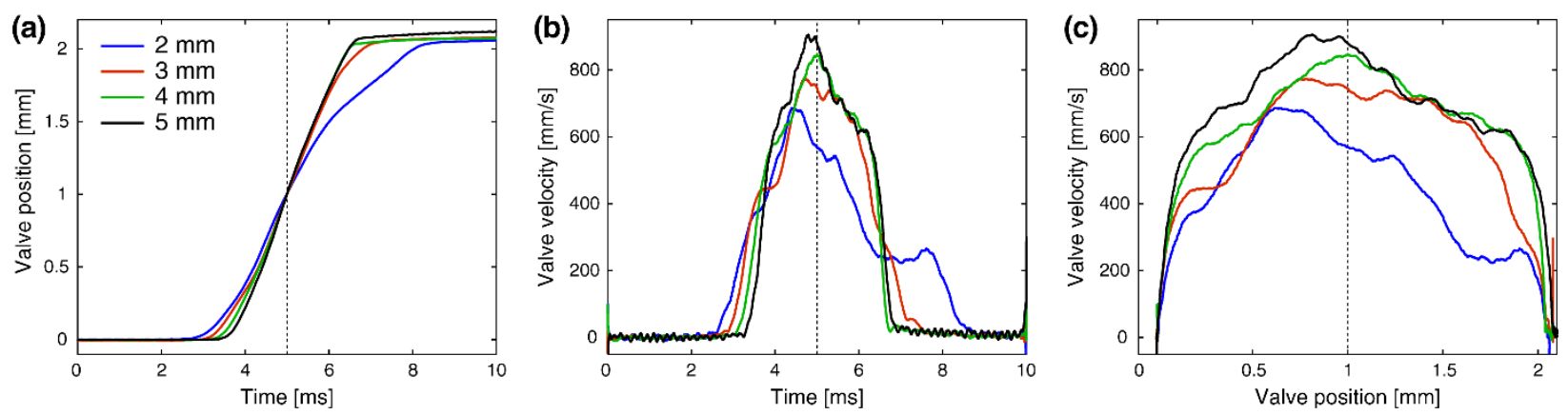

Fig. 4. Valve closing characteristics. (a)-(c), mean valve movement during closing for 2 to $5 \mathrm{~mm}$ orifice over 8 measurements (STD $<2 \%$ of stroke length). The dash-line highlights when the valve enters the pipe. (a), time vs. position: increased flow rate reduced the closing time of the valve. The differences were more distinguishable in the later stage of valve closing. (b), time vs. velocity: the slow-down of the valve in the $2 \mathrm{~mm}$ orifice configuration was distinct. Although the valve movements in the 3-5 $\mathrm{mm}$ configurations were similar, an increase in flow rate resulted in a higher maximum valve velocity. (c), position vs. velocity: for faster closing valves $(3-5 \mathrm{~mm})$, the maximum valve speed was achieved when the valve entered the pipe. For the $2 \mathrm{~mm}$ orifice, the slow-down was more prominent and peaked prematurely compared to the other cases. 

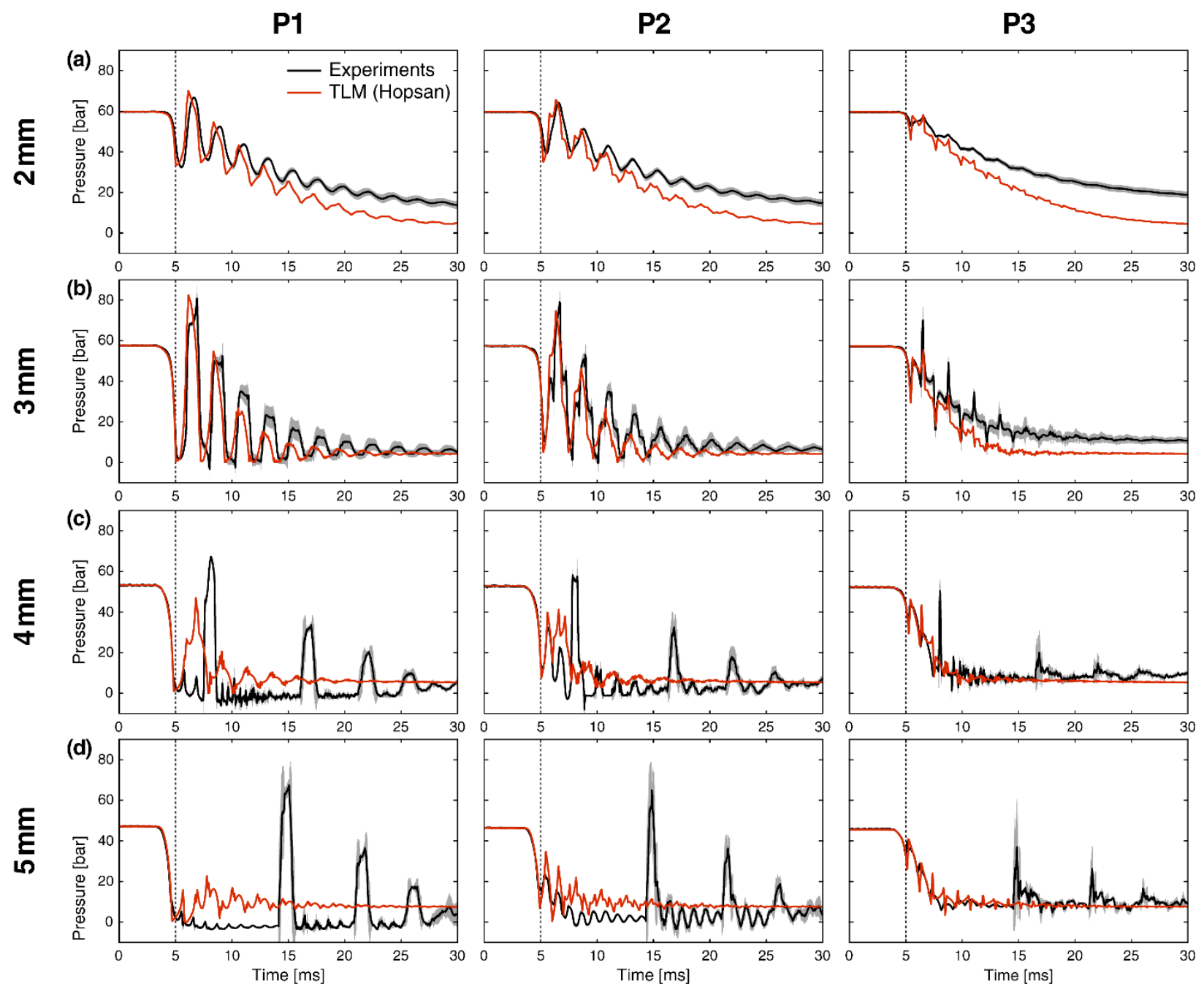

Fig. 5. Pressure response at valve closing. (a)-(d), piezoelectric pressure signals (P1-P3, Fig. 4) and corresponding results from the TLM simulations at four different flow rates (2-5 mm orifice). Data shows the mean (black) and standard deviation (shaded area) over eight measurements, together with TLM results (red). The closing valve enters the pipe at 5 ms (dashed line). (a), low flow rate: system without cavitation and pure water hammer with extensive damping. The characteristics are well captured by the TLM. (b), intermediate flow rate: short-duration pressure peaks suggest cavitation initiation. The TLM still captures the overall characteristics but fail to predict the short-duration pressure peaks. (c, d), high flow rate: large pressure spikes and reduced water hammer effects indicates substantial cavitation. The simulations predict the pressure response until cavitation, whereafter no resemblance can be noticed against experiments. 


\section{Journal of Fluids Engineering}
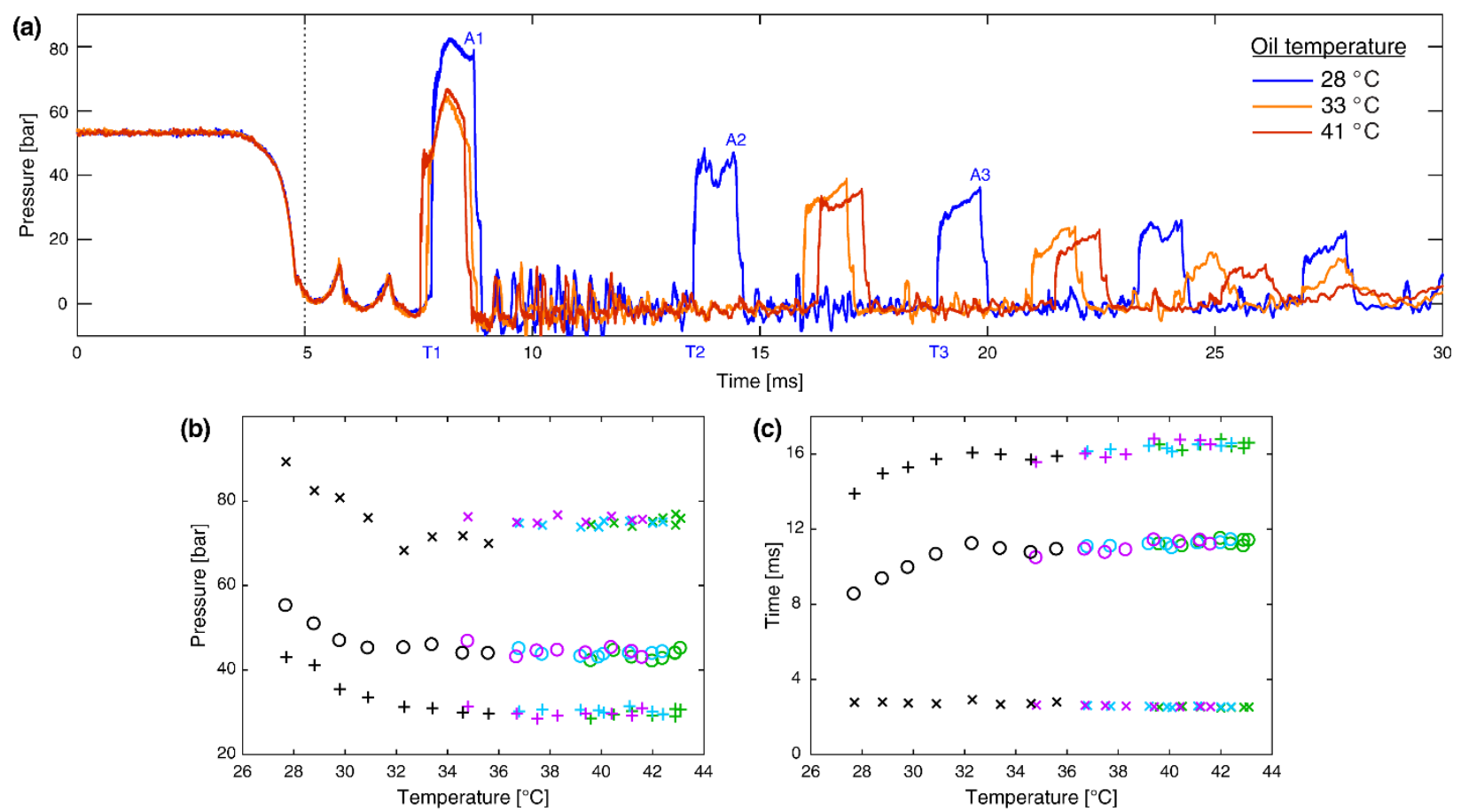

Fig. 6. Oil temperature and pipe angular position. (a), piezoelectric pressure signals (Fig. $4, \mathrm{P} 1)$ at high flow rate (4 mm orifice) and three different oil temperatures. Higher oil temperature tends to delay cavitation onset (time-to-collapse, $1^{\text {st: }}: \mathrm{T} 1,2^{\text {nd: }}: \mathrm{T} 2$ and $3^{\text {rd: }}$ T3) and reduce the pressure amplitude at collapse ( $1^{\text {st }}: A 1,2^{\text {nd }}: A 2$ and $\left.3^{\text {rd }}: A 3\right)$. The time was estimated from moment of valve closing (dashed line). $(\mathbf{b}, \mathbf{c})$, Oil temperature versus collapse amplitude and time delay at P1 for the: $1^{\text {st }}(x), 2^{\text {nd }}(0)$ and $3^{\text {rd }}(+)$ collapse, assessed according to (a). Strongest dependences can be seen for lower temperatures $\left(<32{ }^{\circ} \mathrm{C}\right)$, resulting in higher amplitudes (b) with shorter time to collapse (c), while higher oil tempareature ranges were less sensitive. Colors represent different rotation angles of the pipe (green $=0^{\circ}, \mathrm{cyan}=60^{\circ}$, magenta $=120^{\circ}$, black $=180^{\circ}$ ). The rotation angle affects neither collapse amplitude or time, provided the same oil temperature. 
Journal of Fluids Engineering

\section{APPENDIX}

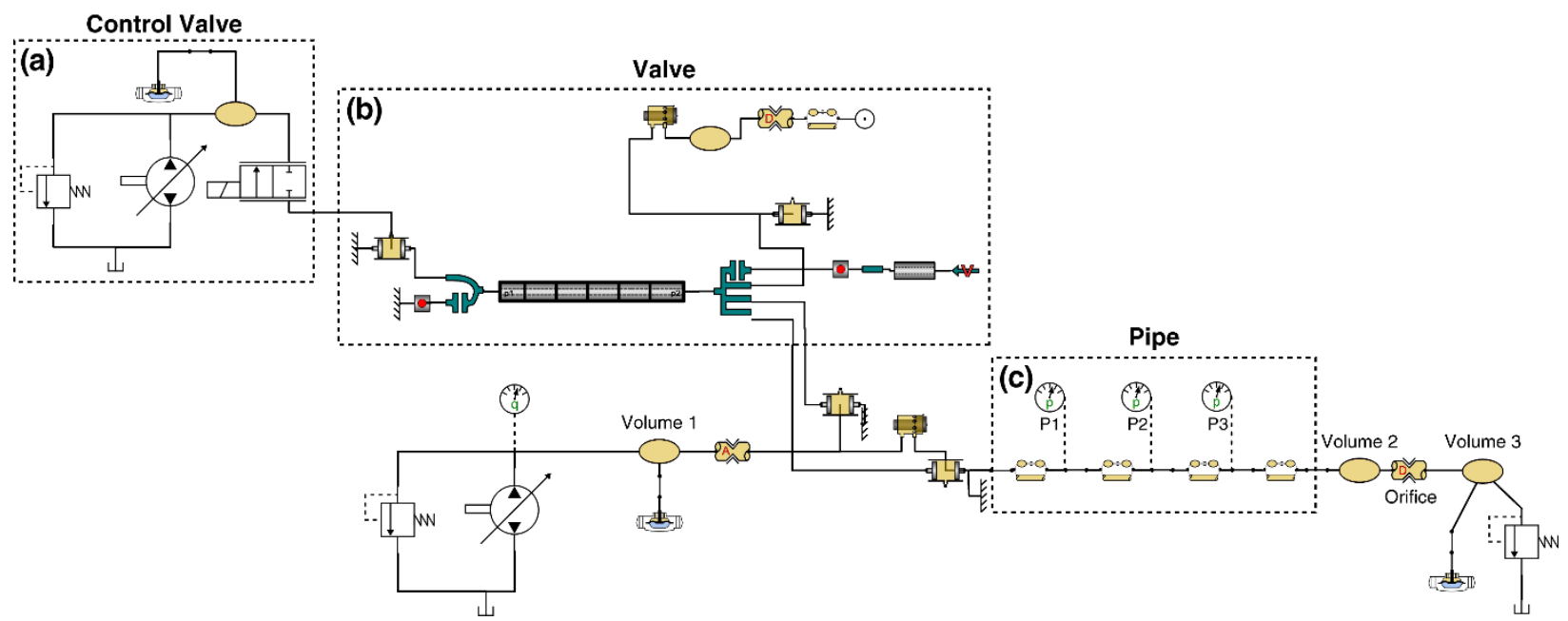

Fig. 7. Transmission Line Model. The test equipment was operated by a control valve (a), which was fed by a variable displacement pump that kept a constant operating pressure. The control valve engages with the valve (b) to stop the pipe flow. The steady flow through the pipe (c) was provided by a variable displacement pump. The system pressure was constant at 60 bar and the flow rate was regulated by the orifice diameter. 


\section{Journal of Fluids Engineering}

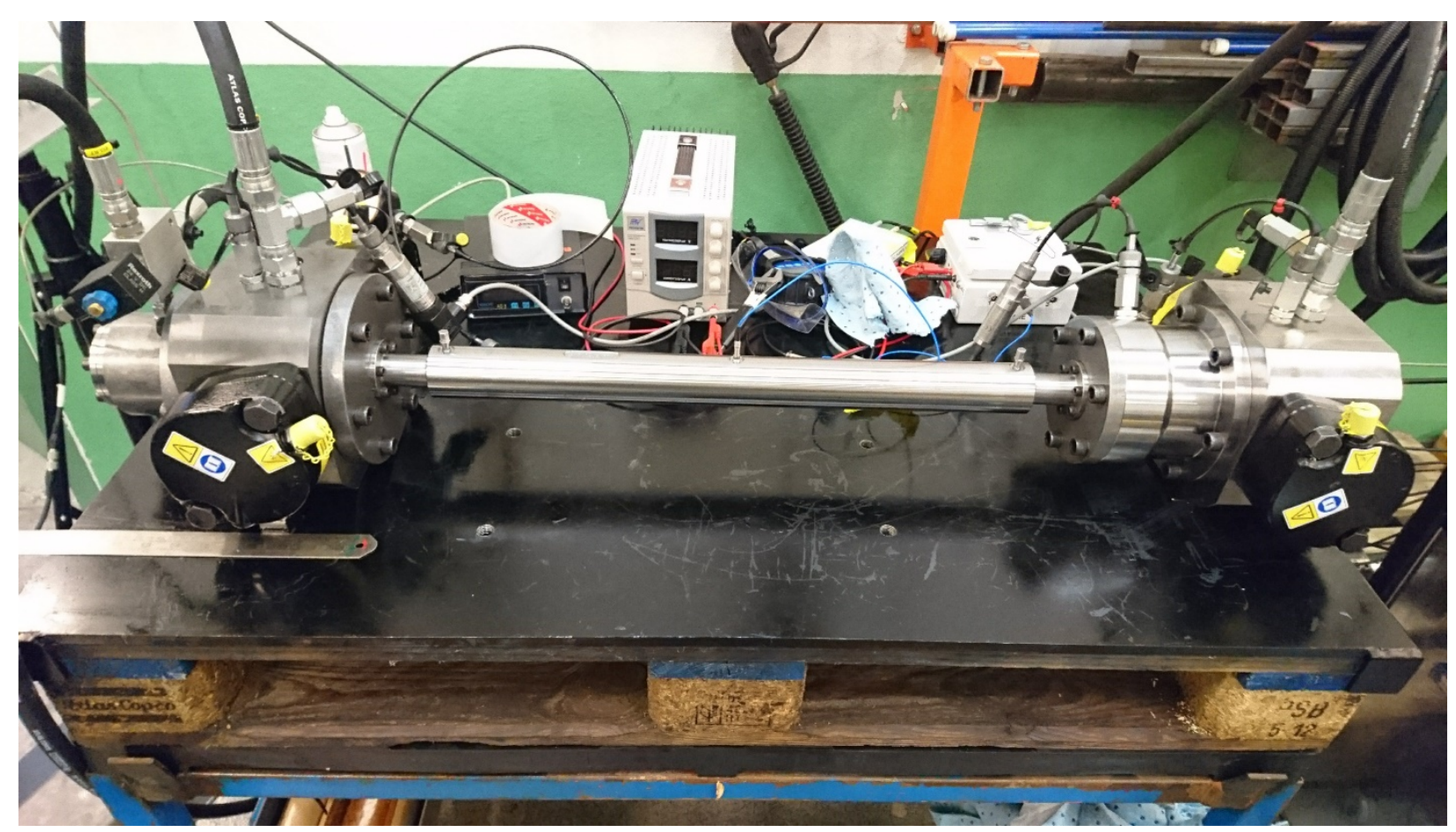

Fig. 8. Test setup. The upstream tank with the valve is located to the left and the two downstream tanks, separated by an orifice, to the right. Piezoelectric pressure sensors are positioned along the pipe (middle). 
(a)

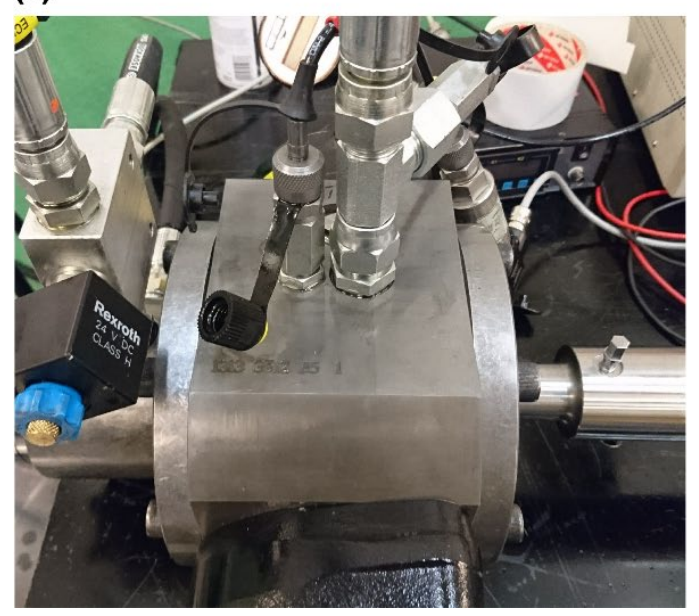

(b)

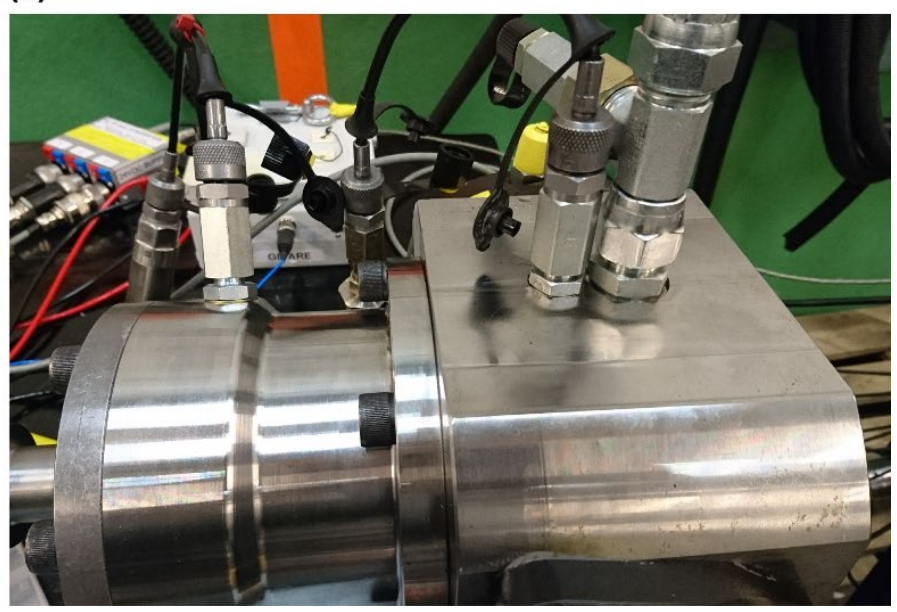

Fig. 9. Silicon pressure sensors and thermoelement. (a), the oil pressure was measured in the tank upstream the pipe with a silicon pressure sensor. The oil temperature was measured with a thermoelement and a multimeter. (b), the pressure was measured both upstream and downstream of the orifice with silicon pressure sensors.

(a)

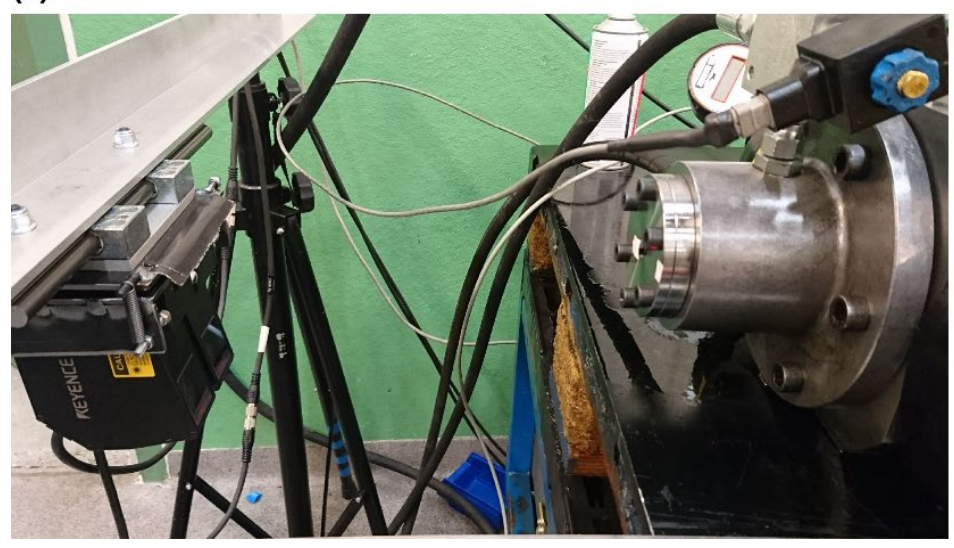

(b)

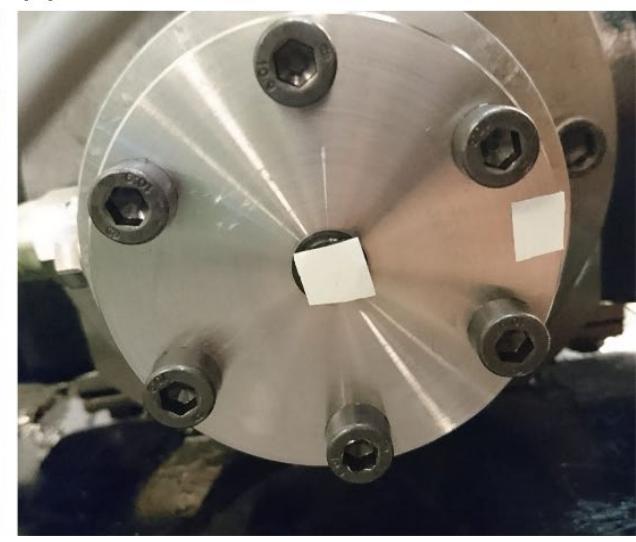

Fig. 10. Laser setup. (a), the two lasers were placed approximately $25 \mathrm{~cm}$ from the valve. (b), one laser measured the valve movement while another laser measured any potential movement of the valve housing. 